\section{Commentary: Surgical aortic valve repair as the primary option for children with congenital aortic stenosis}

\author{
Joseph B. Clark, MD
}

With this latest report, ${ }^{1}$ the group from Melbourne have added to their prodigious work on aortic valve repair in children. Following their earlier experience that demonstrated the superiority of surgical valvuloplasty, ${ }^{2}$ they have abandoned transcatheter intervention for this disease. ${ }^{3}$ While balloon dilatation remains first-line therapy at most centers, ${ }^{4}$ they have sailed against the prevailing wind and adopted an exclusively surgical approach, regardless of patient age or condition. Notably, no patient in the current series underwent balloon dilatation. Overall, their results are excellent, with hospital mortality less than $1 \%$ and freedom from reoperation of $52 \%$ at 10 years. ${ }^{1}$ Although not a comparison study versus catheterization, this report still contributes to the evolving standard against which to judge alternative approaches and should nudge the pendulum ${ }^{5}$ further in favor of surgical valve repair.

Although some initially championed open valvuloplasty for patients beyond the newborn period, ${ }^{6}$ they and others have extended the strategy to include neonates with ${ }^{7}$ or without significant left ventricular dysfunction. ${ }^{8,9}$ In this study, the median age at surgery was just 0.4 years, with neonates accounting for one-quarter of patients. ${ }^{1}$ Survival for neonates was outstanding, with no hospital deaths and just 1 late noncardiac death. Neonates did show a greater risk of reoperation, but not valve replacement. Unfortunately, more granular characteristics and outcomes were not

\footnotetext{
From the Division of Pediatric Cardiac Surgery, Department of Pediatrics, Penn State Health Children's Hospital, Hershey, Pa.

Disclosures: The author reported no conflicts of interest.

The Journal policy requires editors and reviewers to disclose conflicts of interest and to decline handling or reviewing manuscripts for which they may have a conflict of interest. The editors and reviewers of this article have no conflicts of interest.

Received for publication Nov 23, 2021; revisions received Nov 23, 2021; accepted for publication Nov 30, 2021; available ahead of print Dec 3, 2021.

Address for reprints: Joseph B. Clark, MD, Division of Pediatric Cardiac Surgery, Department of Pediatrics, Penn State Health Children's Hospital, 500 University

Dr, H085, Hershey, PA 17033 (E-mail: jclark7@pennstatehealth.psu.edu).

J Thorac Cardiovasc Surg 2022;164:1275-6

$0022-5223 / \$ 36.00$

Copyright (c) 2021 by The American Association for Thoracic Surgery

https://doi.org/10.1016/j.jtcvs.2021.11.066
}

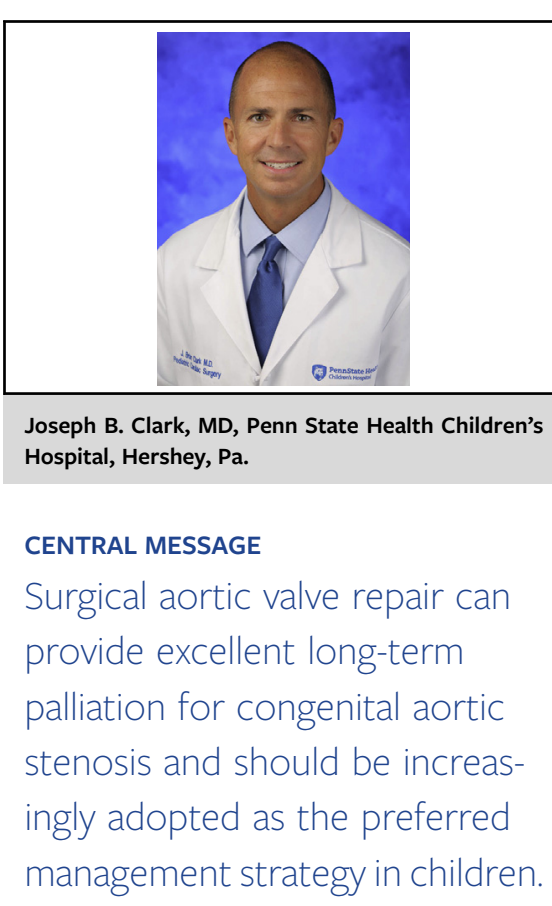

detailed, such as the incidence of preoperative ventricular dysfunction or postoperative complications described in other series such as delayed sternal closure, renal dysfunction, heart failure, and mechanical circulatory support. ${ }^{7}$

Regarding late outcomes, neonates in this study experienced a $32 \%$ freedom from reoperation at 10 years, somewhat lower than the rate of $66 \%$ in another large series. ${ }^{8}$ Could this divergence be due to differences in surgical technique? The Melbourne authors have previously concluded that the addition of patch material to the repair increases the risk of valve failure and reoperation. ${ }^{3,10,11}$ Accordingly, they have advised against the use of patch material whenever possible, and again reiterate this message. ${ }^{1}$ Nevertheless, patches were used in approximately half of the patients in the present study, including neonates. Although patch use did not reach significance as risk factor for reoperation, it trended in that direction $(P=.08)$ and was associated with decreased freedom from valve replacement. On the contrary, patches were strictly avoided in the comparison series with improved freedom from reoperation. ${ }^{8}$ Thus, one may speculate that some of the outcome disparity between these experiences may be due to the development of patch-associated stenosis.

This study does not offer any insight into the advisability of tricuspidization of the bicuspid valve through raphe 
division, either with or without patch support. While some recommend judicious tricuspidization as needed, ${ }^{10}$ others caution against it, especially in infants and young children. ${ }^{6,8,9}$ It can be a difficult dilemma, and one may have to weigh the competing risks of a suboptimal result due to residual stenosis of an intact raphe versus the risk of reoperation due to patch support of the divided raphe. Still, some patch techniques may be less egregious than others. So-called "unrestrictive procedures" (eg, neocommissure triangles) may not impede growth in the same fashion or degree as "restrictive procedures" (eg, leaflet extension or replacement). ${ }^{12}$ Nevertheless, tricuspidization with neocommissure creation may be better applied in older children. $^{8,12}$

Whatever technique is chosen, this study intuitively confirms that the quality of the early surgical result correlates with the durability of the repair. For those with an optimal result (ie, peak gradient $<35 \mathrm{~mm} \mathrm{Hg}$ and trivial or less insufficiency), the freedom from reoperation at 10 years was $78 \%$, twice the rate of those with a suboptimal result. ${ }^{1}$ As the authors comment, these findings should influence intraoperative decision making and encourage an adequately aggressive primary operation on the valve. It appears that the first operation represents a pivotal moment to achieve the best possible early and long-term results, reminding that there is no time like the present.

\section{References}

1. Wallace F, Burratto D, Schulz A, d'Udekem Y, Weintraub RG, Brizard CP, et al. Long-term outcomes of primary aortic valve repair for isolated congenital aortic stenosis in children. J Thorac Cardiovasc Surg. 2022;164:1263-74.e1.

2. Siddiqui J, Brizard CP, Galati JC, Iyengar AJ, Hutchinson D, Konstantinov IE, et al. Surgical valvotomy and repair for neonatal and infant congenital aortic stenosis achieves better results than interventional catheterization. J Am Coll Cardiol. 2013;62:2134-40.

3. d'Udekem Y, Siddiqui J, Seaman CS, Konstantinov IE, Galati JC, Cheung MMH, et al. Long-term results of a strategy of aortic valve repair in the pediatric population. J Thorac Cardiovasc Surg. 2013;145:461-9.

4. Morray BH, McElhinney DB. Semilunar valve interventions for congenital heart disease: JACC state-of-the-art review. J Am Coll Cardiol. 2021;77:71-9.

5. Backer CL. Infant congenital aortic valve stenosis: the pendulum swings. J Am Coll Cardiol. 2013;62:2141-3.

6. Brown JW, Rodefeld MD, Ruzmetov M, Eltayeb O, Yurdakok O, Turrentine MW. Surgical valvuloplasty versus balloon aortic dilation for congenital aortic stenosis: are evidence-based outcomes relevant? Ann Thorac Surg. 2012;94:146-53.

7. Hraska V, Sinzobahamvya N, Haun C, Photiadis J, Arenz C, Schneider M, et al. The long-term outcome of open valvotomy for critical aortic stenosis in neonates. Ann Thorac Surg. 2012;94:1519-26.

8. Vergnat M, Asfour B, Arenz C, Suchowerskyj P, Bierbach B, Schindler E, et al. Aortic stenosis of the neonate: a single-center experience. J Thorac Cardiovasc Surg. 2019;157:318-26.

9. Herrmann JL, Clark AJ, Colgate C, Rodefeld MD, Hoyer MH, Turrentine MW, et al. Surgical valvuloplasty versus balloon dilation for congenital aortic stenosis in pediatric patients. World J Pediatr Congenit Heart Surg. 2020;11:444-51.

10. Tweddell JS, Pelech AN, Jaquiss RD, Frommelt PC, Mussatto KA, Hoffman GM, et al. Aortic valve repair. Semin Thorac Cardiovasc Surg Pediatr Card Surg Annu. 2005;112-21.

11. Siddiqui J, Brizard CP, Konstantinov IE, Galati J, Wheaton G, Cheung M, et al. Outcomes after operations for bicuspid aortic valve disease in the pediatric population. Ann Thorac Surg. 2013;96:2175-83.

12. Vergnat M, Asfour B, Arenz C, Suchowerskyj P, Bierbach B, Schindler E, et al. Contemporary results of aortic valve repair for congenital disease: lessons for management and staged strategy. Eur J Cardiothorac Surg. 2017;52:581-7. 